\title{
article
}

\section{Sustainable care: theorising the wellbeing of caregivers to older persons}

\author{
Norah Keating, norah.keating@ualberta.ca \\ Swansea University, UK; North-West University, South Africa; University of \\ Alberta, Canada \\ J. Allister McGregor, hssjam@bath.ac.uk \\ University of Bath, UK \\ Sue Yeandle, s.yeandle@sheffield.ac.uk \\ University of Sheffield, UK
}

\begin{abstract}
The term 'care crisis' is invoked to denote chronic system failures and bad outcomes for the people involved. We present a comprehensive wellbeing framework and illustrate its practicality with evidence of negative outcomes for those who provide care. We find evidence of substantial material and relational wellbeing failures for family carers and for care workers, while there has been little interest in carers' views of their ability to live the life that they most value. Understanding and improving wellbeing outcomes for carers is an essential component of sustainable care, which requires the wellbeing of the different actors in care arrangements.
\end{abstract}

Key words wellbeing $\bullet$ wellbeing failures $\bullet$ family carers $\bullet$ care workers

To cite this article: Keating, N., McGregor, J. and Yeandle, S. (2021) Sustainable care: theorising the wellbeing of caregivers to older persons, 5(4): 611-630, International Journal of Care and Caring, DOI: 10.1332/239788221X16208334299524

\section{Introduction}

Population ageing is a continuing phenomenon of the 21st century. While what it represents is welcome - for example, reductions in infant mortality and infectious disease and fertility rates, all associated with improvements in human wellbeing - its consequences are a matter of concern for governments and for people. For over 40 years, apocalyptic language such as 'grey tsunami' and 'intergenerational warfare' has been invoked, reflecting anxieties about societies' ability to provide care for rising proportions of older people. Now rightly decried as ageist, the language has softened 
but the term 'care crisis' is frequently invoked in policy, academic and media circles (Dann, 2014; Age UK, 2018; ILO, 2018). The challenge today is how societies can develop care arrangements that will be sustainable in the face of growing care needs and shifting societal sensibilities about care. We argue that sustainability must be conceived of in societal, financial and human terms. As such, we take the term 'care crisis' to connote both chronic system failures and bad outcomes for many of the people involved in care to older persons. System failures are evident in the overloading and/or underfunding of organisations involved in care arrangements, while at the human level, the crisis is manifest as 'wellbeing failures' for people - those who are cared for and those who provide care. At the societal level, the challenge is about how increasing care needs can be met without further exacerbating the socially damaging inequalities that have been growing in nation states (Wilkinson and Pickett, 2009). Sustainable care arrangements are a matter of social justice (Tronto, 2013).

In recent global policy narratives, as well as in care legislation in a number of countries, the concept of 'wellbeing' has been invoked as a way to progress thinking about care arrangements. However, its conceptualisation is varied and often uncritical (Gillett-Swan and Sargeant, 2015). The purpose of this article is to clarify the conceptualisation of wellbeing by presenting a multidimensional model. We illustrate its utility in relation to caregivers to older adults and provide evidence of poor wellbeing outcomes for family carers and for care workers in each of the wellbeing domains. We argue that this work provides a basis for subsequent analysis of what needs to be done and of who needs to act. Our purpose is founded in the belief that care arrangements will only be sustainable where they recognise and attend to the wellbeing needs of all participants in care relationships.

The article proceeds by reviewing how wellbeing is being conceptualised for public policy purposes, noting the recent emergence of wellbeing in relation to care policy. We use a three-dimensional conception of wellbeing to understand different ways that those who care for others (care workers and family carers) fail to achieve a minimally acceptable level of wellbeing in one of more of these dimensions. We focus on the wellbeing failures of caregivers to older people not because wellbeing outcomes for those who are cared for are not important, but because failures for those cared for tend to be more obvious, and are more explicitly signalled as 'scandals' involving physical harm, denial of their autonomy or financial defrauding (Barnes, 2012; Lewis and West, 2014;Age UK, 2019).Wellbeing failures affecting caregivers, on the other hand, evoke less 'scandal', and their marginalisation is characteristic of the systemic undervaluation of care work. We show how these wellbeing failures can be experienced in material, relational and subjective terms. In the conclusion, we discuss the usefulness of conceptualising domains of caregiver wellbeing and point to a way forward in which wellbeing failures might be mitigated and where responsibility for the different types of actions required should lie.

\section{Wellbeing as a public policy framework}

The increasing use of the term 'wellbeing' in policy agendas reflects a broader trend in global public policy. Governments at all levels, and across many policy sectors, have been turning to wellbeing as a reaction to economistic growth strategies that have been neither environmentally sustainable, nor equitable in economic, social or political terms. In 2009, the final report of the Commission on the Measurement of 
Economic Performance and Social Progress ${ }^{1}$ (Stiglitz et al, 2009) gave an injection of intellectual and political momentum to the wellbeing movement. It argued that progress in societies should be gauged in terms of whether they are producing wellbeing improvements for their populations, rather than in merely narrow economic terms (for example, gross domestic product [GDP] per capita). This movement has gathered momentum (Bache and Reardon, 2016; OECD, 2017), contributing one of the key underpinning ideas for the holistic and human-centred vision of the Sustainable Development Goals Declaration of the United Nations General Assembly (UNGA, 2015).

In order to apply the notion of wellbeing effectively in policymaking and policy analysis, it is necessary to be clear about what we mean by wellbeing, and how relevant wellbeing constructs might be used to assess whether care arrangements are sustainable. Kurt Lewin's (1943: 118) oft-quoted maxim that 'there's nothing so practical as a good theory' is relevant here. By good theory, we mean theory that is precise, useful, supported by evidence and broadly applicable. In terms of policy and public decisionmaking, good theory is a formalised and precise presentation of how governments and other formal bodies purport to make decisions about how to act. In social justice terms, good theory provides a framework to address the question: 'What would make care sustainable from the standpoint of the people who provide the care?'

There is much hope and promise in the aspirations of the globalised wellbeing movement. Yet, a major challenge lies in the proliferation of concepts of wellbeing (McGregor, 2018; Austin, 2020). There are two main epistemological perspectives. The first is a set of approaches that conceptualises wellbeing as arising from a personal evaluation of one's situation. Foremost among these are 'happiness', 'quality of life' and 'life satisfaction'. Each has its intellectual and disciplinary roots, epistemology, and distinctive conception of wellbeing. ${ }^{2}$ All are primarily concerned with wellbeing as subjective. They arise, however, from different points on a hedonic-eudaimonic spectrum (Huta and Ryan, 2010; OECD, 2013). Happiness most closely represents a hedonic approach, in which wellbeing is defined as experiencing pleasure. While hedonic notions and measures of wellbeing may have uses for some limited policy purposes (for example, broad-scale national comparisons), they are less helpful for more detailed policy analysis and application (OECD, 2013; Austin, 2016). More eudaimonic notions of wellbeing, such as life satisfaction and quality of life, are focused on the extent to which a person believes themselves to be fully functioning. This has important conceptual connections to other bodies of theory, such as Amartya Sen's (1999) capabilities approach, and affords insights into a more complex set of considerations as to how wellbeing arises. Here, we embrace a more eudaimonic conceptualisation of 'seeking to use and develop the best in oneself' (Huta and Ryan, 2010: 735) as most consistent with the mission of the Sustainable Development Goals 'to leave no one behind'.

A second perspective is that of wellbeing as an objective state arising from having sufficient economic resources. GDP, despite critiques (Waring, 2004; 2018; Stiglitz, 2020), has long been viewed as the main indicator of a nation's economic progress (Allin and Hand, 2017; Calcagnini and Perugini, 2019). However, the recent shift to the wellbeing of the population as a national policy goal (Taylor, 2011; Hall, 2019) has led to a call for measures of progress that incorporate conditions to enhance the lives people are able to lead (Hall, 2019). An example is the Organisation for Economic Co-operation and Development (OECD, 2013:27) framework, in which 
material living conditions are considered as a pillar of wellbeing. These conditions are defined as the economic resources of individuals or households, such as wages, pensions and social transfers (income), and accumulated assets (wealth). Both are seen as important because they enhance people's abilities to choose the lives they wish to lead.

The renewed policy enthusiasm for wellbeing since 2009 can be seen as a story of efforts to bring these two traditions together.Taylor (2011) describes a tension between them, with academic social policy experts considering wellbeing as a social good, while nations have long used an economic understanding of utility that is associated with welfare. Yet, he argues that both are important, as they allow us 'to consider what it means to "be well" alongside what it means to "do well"” (Taylor, 2011: 779).

The catalyst for this integration of the two traditions has roots in the work of Amartya Sen. In his 'capabilities' approach, Sen (1999) argues that understanding wellbeing outcomes requires accounting for both resources and people's evaluations of their ability to be and to do what they value.This position was adopted by the Stiglitz Commission (of which Sen was a co-chair) in 2009. In the multidimensional wellbeing framework proposed by the Stiglitz Commission, and subsequently developed by the OECD, it is clearly stated that neither subjective evaluations nor objective resources are, in themselves, sufficient to give a rounded sense of whether a person is doing well in their life. This view is intuitively plausible and empirically supported by evidence of persons who are doing well in material terms but are nevertheless dissatisfied with the experience of their life and, conversely, people who are doing poorly in material terms but are nevertheless doing well in terms of their subjective wellbeing (Graham, 2010). In a contemporary summary of this approach, from a capabilities perspective, 'wellbeing is about command over physical, social, psychological and environmental resources and the possibilities that they make available to an individual' (Stephens and Breheny, 2019: 23).

The importance of the social is a third theme in wellbeing theorising. Sen (1999) argues that the relationships that people have enable (or constrain) them and are thus vital in whether they are able to exercise their 'capabilities'. Others make the point that by incorporating a social dimension of wellbeing, we recognise that 'all humans are vulnerable and fragile', and that 'agency itself may be found within social relationships as much as in autonomous individual action' (Tronto, 2017: 32). The adoption of a relational dimension of wellbeing emphasises the assumption that in order to be well, we need supportive connections to others.

Taking this logic forward, we have developed a conception of wellbeing with three dimensions (material, relational and subjective) that is applicable to caregiving. Thus, wellbeing arises from what a person has (the material), what they can do through their relationships with others (the relational) and how they feel and evaluate what they have and can do (the subjective) (McGregor, 2007; McGregor and Pouw, 2017). Together, these dimensions can offer a rounded view of how a person is managing to be in their life.

\section{Inclusive growth and multidimensional models of wellbeing}

Wellbeing is being applied in contemporary policymaking in a desire to make the experience of societal development more positive for people in the societies they live in. This is timely in the wake of the global economic crisis and rising inequalities in 
Europe (Lindberg, 2019). Framed as an approach to 'inclusive growth', ${ }^{3}$ it defines and measures policy options and trade-offs, both to address inequalities and to promote economic growth. It specifically targets three types of inequalities: vertical (between people at the top and bottom of the income distribution); horizontal (between different groups of people, including by gender and age); and wellbeing deprivations (the share of the population falling below a threshold value or standard of wellbeing) (OECD, 2017). In concert with the mission of the Sustainable Development Goals to 'leave no one behind', wellbeing is at the core of this agenda and has been taken up by many governments and international organisations (for example, UNGA, 2015; UNDP, 2017; WEF, 2017; OECD, 2018).

\section{Wellbeing in care policy}

In the 2020s, a number of countries are seeking to make use of wellbeing as an organising concept for national policymaking. These include countries that are systematically gathering wellbeing data for policy monitoring and evaluation purposes, such as Italy and Germany (Calcagnini and Perugini, 2019; Kickbusch et al, 2019), and countries that are actively seeking to push the concept into policymaking. In 2018, New Zealand launched a Wellbeing Budget (New Zealand Treasury, 2018). In the UK, the Office of National Statistics has been collecting multidimensional wellbeing data since the launch of the Measuring National Wellbeing Programme in 2011 (ONS, 2019), while the Canadian Wellbeing Index (Canadian Index of Wellbeing, 2016) is used by provinces and municipalities to inform strategic planning and policy development.

Despite these advancements, the application of wellbeing to particular policy spheres has been patchy, and the language used has been imprecise. In the area of care to adults, most policy documents are in the form of guidelines. An example is the international non-governmental organisation (NGO) AGE Platform Europe, which has produced a 'toolkit for policymakers and practitioners who would like to evolve towards ensuring the wellbeing and dignity of older persons in need of care' (AGE Platform Europe, 2019:3). Its goals are framed in human rights, with aspirations that are laudable but, perhaps, unenforceable.

In contrast, in the UK, wellbeing is now central to legislation on care (Hamblin, 2019). The Care Act 2014 (applicable in England) is a legislative framework that positions the wellbeing of carers (and of adults in need of care) at the heart of national care policy (Department of Health, 2014; Clements, 2016: 12-13). ${ }^{4}$ The legislation draws on mixed theoretical foundations that are not always consistent with each other, and may even be contradictory. Such theoretical permissiveness results in 'room for manoeuvre' that, in our view, puts at risk the social justice agenda so fundamental to wellbeing. Examples from other jurisdictions show that the financial wellbeing of formal care systems can be positioned as 'prudent' (Addis et al, 2019), and that the increased workloads of family carers can be presented as enhancing their wellbeing through 'co-production' (Kodate and Timonen, 2017: 301). The wellbeing of carers, central to the 2014 legislation in England, is (at best) muted through the prioritisation of the financial aspects of system wellbeing.

Such tensions between the decisions governments take and the values that drive them are hallmarks of the policy process (Keating and Cheshire-Allen, forthcoming). In the next section of the article, we challenge such theoretically permissive approaches 
to wellbeing by employing a multidimensional theory of wellbeing with distinct material, relational and subjective components (McGregor, 2018). We use this theory as a foundation for creating evidence of wellbeing outcomes, and for moving towards a values-based argument that calls for consistent (and thus equitable) treatment of people whose wellbeing may be at risk.

\section{The wellbeing of family carers and care workers}

To illustrate the value of using a multidimensional conception of wellbeing to better understand, and address, the care crisis, we now look to empirical research that illustrates how different actors in care arrangements currently experience wellbeing failures. We consider the wellbeing of two types of caregivers (family carers and care workers) and provide evidence of diminished material and relational wellbeing for both. Despite large bodies of research on carers and care workers (Leichsenring et al, 2013; Moen and DePasquale, 2017; Eurofound, 2020), we have insufficient information on carers' perspectives on how care influences their ability to be and to do what they most value. The relative invisibility of the lives of those who care is suggestive of scant regard for their wellbeing deprivations.

Before discussing wellbeing failures, it is helpful to sketch the two groups we focus on. Carers are 'people with an ongoing, personal connection to the cared-for person based on close kin connections or long-standing friendships' (Keating et al, 2019: 150). Researchers have positioned the work of carers as stemming from relationships that are variously motivated by love, reciprocity or obligation (Finch, 1989; Keating and Eales, 2017). In contrast, care workers are engaged through 'a contractual relationship to provide supportive services' (Dahlberg et al, 2018; Keating et al, 2019: 150).

Although there are considerable differences between carers and care workers, what is common to both is the nature of the work itself. Providing care is highly personal and emotionally challenging, and largely hidden from, or ignored by, others in society. Yet, it is primarily in reference to care workers that we see powerful and negative descriptions of care labour. It has been argued that aged care is 'dirty work', affected by the physical taint of tasks requiring intimate touch and bodily wastes, and the social taint of association with the 'non-productive, ageing, leaky bodies of care recipients' (Clarke and Ravenswood, 2019: 90).

Regardless of its devaluation, care labour is widespread (ILO, 2018). In England alone, nearly 1.5 million people (mostly women) work in adult social care; the vast majority are care workers who provide direct service (Skills for Care, 2020). While their numbers have risen modestly over the past five years, estimated need far outstrips this growth (Beech et al, 2019). The number of people caring for family members or friends is even larger; estimates for the UK put their number at over 8.8 million people in 2019, rising to well above this number during the COVID-19 pandemic (Carers UK, 2019; 2020).

In the next section, we provide evidence of the wellbeing failures experienced by family carers and by care workers, highlighting the fragility of the care sector. We did not conduct a systematic review. Instead, the examples provided are illustrative and meant to support the conceptual framing of wellbeing that we are proposing. 


\section{Components of carers' wellbeing}

Family carers' wellbeing is predicated on assumptions that they are 'natural' carers. Metaphors such as 'working for love' reflect and entrench the belief that care work is unskilled, has no boundaries around time spent and need not be compensated or paid (Briar et al, 2014: 123). Palmer and Eveline (2012: 257) speak of a 'familial care logic' that socialises, in particular, women into feeling that care should be given altruistically for emotional and relational, rather than material, rewards. Researchers have challenged such assumptions as ones in which 'care trumps justice' (Hankivsky, 2014: 254).

\section{Material wellbeing}

Family carers incur substantial material costs (Keating et al, 2014; Bauer and SousaPoza, 2015). Considerable attention has been given to the effects of caring on carers' labour force participation (Kröger and Yeandle, 2013). Overall, carers have lower rates of attachment to the labour force (Van Houtven et al, 2013) - a neutral phrase that belies the ways in which they are excluded. Carers may be unable to enter the labour force, reduce their labour force participation because they find caring and employment incompatible, or be unable to find employment after a period of family care.

Those who become carers at younger ages are at risk of truncated educational opportunities and difficulties in gaining the necessary qualifications or experience for job entry (Yeandle and Buckner, 2007; Joseph et al, 2019). Labour force preclusion (Fast, 2015) or a lifetime of precarious labour force attachment may follow. Among carers who are employed, increasing numbers are leaving employment or reducing their engagement (Austen and Ong, 2013). This exodus is gendered. Women are more likely than men to retire to provide care, to decrease their work hours and to have lower wages than non-carers. In most studies, caring is shown to have less effect on the working hours or wages of men (Van Houtven et al, 2013; Gomez-Leon et al, 2019).

Finding jobs that are compatible with care responsibilities is especially difficult for those at the low-skill end of the job market (Bauer and Sousa-Poza, 2015). Regardless of carers' place in the life course, reductions in labour force engagement are associated with loss of income, pensions and other benefits (Duncan et al, 2020). Remaining in the labour force is often a financial necessity and important for social security in later life (Sardadvar and Mairhuber, 2018).

Further erosion of carers' material wellbeing comes from the additional costs they incur in purchasing goods or services, making household adaptations, and covering the transport costs involved in supporting the person they care for. Carers who report care-related out-of-pocket expenditures have higher levels of stress, provide more intense levels of care and live at a distance from the care receiver (Duncan et al, 2016;2020).

Such expenses have long been documented in settings that lack universal health or chronic care coverage. In a national study in the US, 78 per cent of family carers reported out-of-pocket expenses, with low-income carers experiencing significant financial strain (Rainville et al, 2016). There are associated indirect costs as well. Carers may forgo services for themselves, including healthcare, because they cannot afford insurance premiums or the co-payments required for treatment (Mosher et al, 2015). 
Yet, even in countries where some carers are eligible for state financial transfers, managing these expenses can be financially difficult. Australia has financial benefits that some carers can receive: the Carer Payment, that is, help for carers who cannot undertake paid work because of caring, and the Carer Allowance, which is designed to help them with the additional costs of caring above their usual costs of daily living (Yeandle et al, 2012). In the UK, Carers Allowance is paid to a minority of carers who have no or only very low personal income from paid employment, but it is generally considered too low to offset the extra costs of caring. Also in the UK, the National Audit Office (NAO, 2018) has estimated that in 2016/17, people spent $\mathcal{N}_{10.9}$ billion on privately purchased social care. Carers pay care expenses by drawing on savings, reducing necessary purchases and forgoing the 'little extras' that make life enjoyable (Lai, 2012; Duncan et al, 2016). Across jurisdictions, few carers receive financial supports to defray these costs (Duncan et al, 2016; Spasova et al, 2018).

Calculation of the extent of carers' out-of-pocket expenses would benefit from large-scale, comparative studies from which to compare costs across settings or over time. Despite a long-standing concern about the effects of welfare state retrenchment, we lack coordinated efforts to track the extent to which carers assume the economic impact of care. Out-of-pocket expenses remain one of the hidden costs of care.

\section{Relational wellbeing}

One of the long-standing beliefs about family care is that carers are embedded in family networks that share care responsibilities and care work (Shanas, 1979). Structural changes in families, such as lower birth rates and greater fluidity in family membership, are positioned in some accounts as the main threats to family carers' relationship resources (Roberto and Bleiszner, 2015). Yet, assuming that lack of family care capacity is a matter of having sufficient 'warm bodies' flies in the face of growing evidence that family interactions can threaten relational wellbeing in the context of care. In a systematic review of the social consequences of care, Keating and Eales (2017) found reduced wellbeing in relationships with the cared-for person and in relationships with other family members, especially spouses, siblings and children.

Carers for diverse family members experience a variety of losses: spouse carers of companionship and emotional connectedness; child carers of strong, independent parents; and brother or sister carers of the companionship of an egalitarian relationship with their siblings. For some, there is a feeling of being trapped and unable to leave due to feelings of obligation and/or a lack of care alternatives (Mizuno et al, 2011). Carers' may experience distress at spillover effects on their own families, such as having insufficient time for their own children or negative impacts on their marriages. The needs of the person requiring care often take precedence over the plans of carers and their partners (Reczek and Umberson, 2016). Conflict and tension with family members may arise from lack of understanding or assistance from family members who were expected to help.A family history of conflict exacerbates family tensions (Kramer and Boelk, 2015).

Disruption of broader social networks marks a second source of relational wellbeing failures (Keating and Eales, 2017). Many carers feel alone; social isolation can result from friends making less effort to include them or from carers keeping others away who do not understand their situation or are unsupportive (Keating and Eales, 2017). Some carers describe their social lives as 'non-existent' (Rossen et al, 2013). 


\section{Subjective wellbeing}

Our understanding of carers' subjective wellbeing comes almost entirely from their evaluation of the caring work they do. For over 30 years, evidence has been accumulating of personal feelings of strain resulting from care. The concept of 'caregiver burden' has been used extensively to capture negative aspects of family care. Findings show that among spouse carers, subjective burden (the person's evaluation of strain resulting from their caring role) is associated with poor physical and mental health, loneliness, and poor quality of life (Zarit et al, 1986; Fekete et al, 2017).

Recent findings indicate that carers also experience guilt about what they perceive as their failure to provide sufficient care for a terminally ill relative (Bennett, 2018). Carers of relatives with dementia at the end of life experience psychological distress and anxiety, often feeling unable to care as they think they should (Moore et al, 2017). Some believe they are not suited, psychologically or emotionally, to be carers, but feel they have no chance to opt out of caring (Rand and Malley, 2014).

We know little of carers' views of their ability to live the life they most value. Cunningham et al (2018:11) argue that the 'loss-deficit model of caregiving' is too narrowly focused and that burden continues to dominate the wellbeing field. This is a significant gap in understanding of wellbeing outcomes for family carers. This lacuna is not surprising. Increasingly, European policy agendas have become focused on addressing what carers need to manage caring alongside other roles (like paid work) and to sustain the care they provide (European Commission, 2017; Yeandle, 2020). Leslie et al (2019) contend that needs-based approaches are set within power hierarchies in which others determine how needs are assessed, what level of need warrants support and how scarce resources are allocated. They advocate a shift to carer goals or personal aspirations as a way to leverage strengths, offer hope and remedy power imbalances (Peacock et al, 2010, cited in Leslie et al, 2019).

\section{Components of the wellbeing of care workers}

The wellbeing of care workers is predicated on assumptions, equally often unexamined, that are similar to those about family carers. Care jobs are seen as well suited to women because they are 'natural' carers in paid and unpaid caring roles (Clarke and Ravenswood, 2019: 84). Accordingly, care workers often tolerate poor pay and conditions, as many women find care work satisfying and intrinsically rewarding (Hebson et al, 2015). As with family carers, much of the evidence belies such assumptions.

\section{Material wellbeing}

There is substantial evidence of challenges to care workers' material wellbeing. These arise mostly from inadequate or uncertain income and poor working conditions. In multiple jurisdictions, organisations are implementing 'zero-hour contracts' in which there are no guaranteed minimum hours of employment (Koumenta and Williams, 2019). Critics says that these jobs are associated with low-quality employment, low wages and income uncertainty (Delp et al, 2010; Belgiojoso and Ortensi, 2019; Skills for Care, 2020). 
Material wellbeing varies across sectors (Eurofound, 2020). Community-based workers have lower job stability, earn less, work fewer hours and are less likely to have fringe benefits than those employed in hospital and nursing home settings (Hewko et al, 2015). Migrant care workers are at particular risk given their precarity of employment, housing and lack of social relationships (Boccagni, 2016:285). Live-in carers may be excluded from national laws regulating overtime pay (Mundlak and Shamir, 2011), entrenching substandard working conditions, such as work overload and low worker control (Braedley et al, 2018). They are particularly vulnerable to long work hours (Carlos and Wilson, 2018).

In the face of such working conditions, it is unsurprising that organisations have difficulty attracting and retaining employees (Austen et al, 2013). In 2017/18 alone, there was a 37.5 per cent turnover in care work positions in the UK (Skills for Care, 2020). Kaine (2012) argues that care sector jobs are chosen by people with limited formal qualifications but with access to 'feminine' cultural capital that establishes care work as something at which they are unlikely to fail. High turnover in the care work sector belies its meaningfulness and threatens its sustainability. Continued undervaluation of their work adversely impacts those who provide care, as well as those for whom they care (Hewko et al, 2015).

\section{Relational wellbeing}

The focal relationship in the paid work of care is between care workers and care receivers, often mediated by relationships with the family members of the person they care for. Some care workers develop a strong sense of attachment to their clients (Elliott et al, 2013). Such relationships have been described as 'kin-like', especially when negotiated within the domestic space of the care receiver (Baldassar et al, 2013).

Yet, such negotiations do not always go well. A study of migrant long-term live-in care workers in Taiwan found that they had close emotional and quasifamilial relationships with family members (Lin and Bélanger, 2012) but that their asymmetrical power relationships placed them in a position of continuously having to negotiate contradictory feelings and tensions in the intimate sphere of their employers' private homes. They had become indispensable to the families, but their dependency and domestic intimacy placed them at risk of abuse.

There is evidence that live-in carers and community care workers desire more contact with co-workers (Elliott et al, 2013), and both supervisor and co-worker communication and support have been shown to be important in psychological health (Gao et al, 2017).Yet, relational issues of disrespect and discrimination are pervasive across work settings (Braedley et al, 2018). Residential care aides, for example, report tensions between expectations that they will form close relationships with patients and families and the under-recognition by members of the team of their efforts to navigate these relationships (Lai et al, 2018). Lack of recognition of support workers' contribution to society, and continued undervaluation of their work, adversely impacts those who provide care and those they care for (Hewko et al, 2015; George et al, 2017).

\section{Subjective wellbeing}

As with family carers, understandings of the subjective wellbeing of care workers comes from their evaluation of their care work. In the case of care workers, knowledge 
is even more fragmented and contradictory, and the issue of satisfaction with care work is itself contested.

Some researchers have argued that care workers are often not asked about job satisfaction because their work is considered undesirable, a 'career-less job' with lack of career growth opportunities and where job satisfaction is unlikely (Belgiojoso and Ortensi, 2019; Mapira et al, 2019: 4). Where research on job satisfaction has been conducted it is often in the context of propensity to leave their jobs (Denton et al, 2007; Edvardsson et al, 2011;Virdo and Daly, 2019). In this research, more supervisor support and assignment of more social care tasks were associated with higher job satisfaction and lower propensity to quit.

Hebson et al (2015) argue that we should not take job satisfaction at face value. They suggest the importance of articulating the trade-offs: accepting the poor-quality aspects of care jobs based on need for local employment, lack of formal qualifications and encouragement from others to take up the job. If we consider the difficult tradeoffs between undesirable low-wage employment options and the need to contribute to their own families' financial wellbeing, expressions of work satisfaction may not constitute evidence of positive wellbeing outcomes.

These apparent contradictions make it even more important to ascertain care workers' views about their ability to live the life they most value. Understanding care workers' life goals seems especially relevant to achieving sustainable care. The fragility of this sector is evident almost everywhere. Does societal indifference to care workers' subjective wellbeing further exclude a group of workers that is already marginalised?

\section{Towards wellbeing and care}

We have structured this article following the tenets of 'good theory' set out in the introduction. Using a wellbeing theory that is formalised and precise, we have employed its three domains to frame our examination of the wellbeing failures of family carers and care workers. In this final section of the article, we return to these dimensions, suggesting areas in which they may be expanded and the values and beliefs that may set boundaries around possibilities for action.

For both family carers and care workers, our exploration suggests that material wellbeing relates to their economic status, though in different ways. The evidence for carers is of what they lose: in employment and income, as well as in out-of-pocket expenses. The evidence for care workers is of the limitations in what they gain through employment in a sector where low and uncertain income is a constant. There has been little explicit examination of what constitutes a minimally acceptable level of material wellbeing for either of these groups. Should carer benefits that are available in some countries be viewed as public sector statements about basic levels of material wellbeing for family carers? Do zero-hour contracts represent indifference to wellbeing failures on the part of employers? Further, if material wellbeing encompasses 'what a person has', we need to consider the extent to which community resources, such as quality of housing, or personal resources, such as health, should be considered elements of material wellbeing.

The relational domain encompasses the supportive connections to others that enhance people's ability to 'be well'. However, our exploration suggests that for both groups of caregivers, the research focus has been narrower - on relationships that help them 'do well' in their care work. For carers, we found an emphasis on 
wellbeing failures in connections to family members and to their social networks that may be unsupportive or unavailable. For care workers, they are with supervisors and co-workers, as well as with their clients.

If we think of relational wellbeing as an indication of what caregivers can do through their relationships with others, it is important to further explore which relationships matter. What is the place of workplace relationships for family carers in affording connections that are not focused on care? For care workers, how might concern about family members left behind by those who have migrated for work, or worry about how their own children will thrive given their uncertain economic status, influence their ability to 'do well' in their care work or 'be well' in their lives?

The subjective wellbeing of caregivers has been based on their evaluation of their care work. For many years, researchers have examined family carers' evaluation of their care work through such constructs as caregiver burden. To our knowledge, there has been less engagement with the question of what levels of burden constitute minimally acceptable levels of reduced wellbeing. Care workers are sometimes asked about job satisfaction, either directly or through assessment of their propensity to leave their jobs. There is much to be learned about the situations in which these workers evaluate whether the trade-offs inherent in care work are worth it.

Questions that arise from these findings return us to sustainability and social justice agendas. In many ways, the future of the care sector seems assured, with heightened demand and projected growth needed to meet the demand. Yet, if carers and care workers are unable or unwilling to care, the care sector may be unsustainable. The language of wellbeing and of wellbeing failures requires engagement with questions of what is minimally acceptable and who is most at risk of experiencing wellbeing failures.

The wellbeing framework can be useful in determining which groups of caregivers might be most at risk of wellbeing failures, and in which domains. For example, do care workers with insecure income and job precarity experience greater material wellbeing failures than those with more secure employment contracts? Do family carers caring for more than one person or who have been caring for a long period of time risk profound failures in relational wellbeing? If decisions are made by others about how caregiver needs are assessed, and what support is warranted, what is the likelihood of failures in subjective wellbeing?

Addressing these questions will provide a basis for determining who should act and who is likely to act. Recent policy initiatives to enhance the sustainability of care have shown little promise of enhancing the wellbeing of those who provide care. Kodate and Tinomen (2017: 291) trace what they call the 'stealthily growing role of family carers' across countries in Asia and Europe. They show how various changes in formal home care policies have resulted in family carers being encouraged, or required, to increase their involvement in care. Da Roit and Moreno-Fuentes (2019: 5) examine how diverse policy approaches in Europe have resulted in informal markets and families being, once again, expected to solve the care needs of ageing populations. Their examples include the de-professionalisation of care provision in Spain that left family carers without formal assistance, as well as Italy's approach to managing large-scale migration that created an underground economy of female care workers. Despite diverse policy goals, the outcomes coalesce towards pushing caregivers further into precarity.

Inevitably, these difficult policy questions give rise to disagreements about what is valued and how to act (Muers, 2018). Governments' ideological approaches to societal 
solutions are one source of disagreement.Yet, across the political spectrum, governments have acted in ways that do little to alleviate wellbeing failures for caregivers.

It is time to augment these policy discussions with a critical examination of societal beliefs about whether older people and their caregivers are deserving of full citizenship (Keating and Cheshire-Allen, forthcoming). It is at the nexus of political ideology and societal values that we can come to understand the deepening wellbeing failures that carers experience, and the extent to which action towards sustainable care is likely.

\section{Notes}

${ }^{1}$ Hereafter referred to as the Stiglitz Commission.

2 For 'happiness', see Layard (2006); for 'quality of life', see Michalos (2011); and for 'life satisfaction', see Diener et al (2013).

3 The OECD describes this agenda as one in which economic models are revisited and lessons are learned from the economic crisis that began a decade ago. The goal is to deliver a strategic policy framework that defines and measures 'inclusive growth', and sets out the policy options and trade-offs that will promote both growth and inclusivity (see: www.oecd.org/inclusive-growth/about.htm).

${ }^{4}$ For the Care Act 2014, see: www.legislation.gov.uk/ukpga/2014/23/contents

\section{Funding}

The authors gratefully acknowledge the support of the Economic \& Social Research Council (award ES/P009255/1, 'Sustainable Care: Connecting People and Systems', 2017-21, Principal Investigator Sue Yeandle, University of Sheffield).

\section{Conflict of interest}

The authors declare that there is no conflict of interest.

\section{References}

Addis, S., Holland-Hart, D., Edwards, A., Neal, R. and Wood, F. (2019) Implementing prudent healthcare in the NHS in Wales: what are the barriers and enablers for clinicians?, Evaluation in Clinical Practice, 25(1): 104-10. doi: 10.1111/jep.13023

AGE Platform Europe (2019) Dignity and wellbeing of older persons in need of care: our shared responsibility, toolkit for policymakers and practitioners, http:// publications.age-platform.eu/opcare-toolkit/.

Age UK (2018) Care in crisis, www.ageuk.org.uk/surrey/about-us/news/ articles/2018/care-in-crisis/.

Age UK (2019) Safeguarding older people from abuse, Factsheet 78, www.ageuk.org. uk/globalassets/age-uk/documents/factsheets/fs78_safeguarding_older_people_ from_abuse_fcs.pdf.

Allin, P. and Hand, D.J. (2017) From a system of national accounts to a process of national wellbeing accounting, International Statistical Review, 85(2): 355-70. doi: 10.1111/insr.12215

Austen, S. and Ong, R. (2013) The effects of ill health and informal care roles on the employment retention of mid-life women: Does the workplace matter?, Journal of Industrial Relations, 55(5): 663-80. doi: 10.1177/0022185613494648

Austen, S., McMurray, C., Lewin, G. and Ong, R. (2013) Retaining workers in an ageing population: insights from a representative aged and community care organisation, Australasian Journal on Ageing, 32(1): 41-6. doi:10.1111/j.1741-6612.2012.00599.x 
Austin, A. (2016) On well-being and public policy: are we capable of questioning the hegemony of happiness?, Social Indicators Research, 127: 123-38. doi: 10.1007/ s11205-015-0955-0

Austin, A. (2020) A Universal Declaration of Human Well-being, Eastbourne: Palgrave Macmillan.

Bache, I. and Reardon, L. (2016) The Politics and Policy of Wellbeing: Understanding the Rise and Significance of a New Agenda, Cheltenham: Edward Elgar.

Baldassar, L., Ferrero, L. and Portis, L. (2013) 'More like a daughter than an employee': the kinning process between migrant care workers, elderly care receivers and their extended families, Identities, 24(5):524-41. doi:10.1080/1070289X.2017.1345544

Barnes, M. (2012) Care in Everyday Life: An Ethic of Care in Practice, Bristol: Policy Press.

Bauer, J. and Sousa-Poza, A. (2015) Impacts of informal caregiving on caregiver employment, health, and family, Population Ageing, 8: 113-45, doi: 10.1007/ s12062-015-9116-0

Beech, J. et al. (2019) Closing the gap: key areas for action on the health and care workforce, www.nuffieldtrust.org.uk/files/2019-03/heaj6708-workforce-fullreport-web.pdf.

Belgiojoso, E. and Ortensi, L. (2019) Satisfied after all? Working trajectories and job satisfaction of foreign-born female domestic and care workers in Italy, Journal of Ethnic and Migration Studies, 45(13): 2527-50. doi:10.1080/1369183X.2018.1465401

Bennett, M. (2018) Blameless guilt: the case of carer guilt and chronic and terminal illness, International Journal of Philosophical Studies, 26(1): 72-89. doi: 10.1080/09672559.2017.1416422

Boccagni, P. (2016) Searching for well-being in care work. Migration: constructions, practices and displacements among immigrant women in Italy, Social Politics, 23(2): 284-306. doi: 10.1093/sp/jxv031

Braedley, S., Owusu, P., Przednowek, P. and Armstrong, P. (2018) We're told, 'suck it up': long-term care workers' psychological health and safety, Ageing International, 43: 91-109. doi: 10.1007/s12126-017-9288-4

Briar, C., Liddell, E. and Tolich, M. (2014) Still working for love? Recognising skills and responsibilities of home-based care workers, Quality in Ageing and Older Adults, 15(3): 123-35. doi: 10.1108/QAOA-04-2014-0006

Calcagnini, G. and Perugini, F. (2019) Social capital and well-being in the Italian provinces, Socio-Economic Planning Sciences, 68:1-10. doi:10.1016/j.seps.2018.11.005

Canadian Index of Wellbeing (2016) How Are Canadians Really Doing? The 2016 CIW National Report. Waterloo, ON: Canadian Index of Wellbeing and University of Waterloo. https://uwaterloo.ca/canadian-index-wellbeing/sites/ca.canadianindex-wellbeing/files/uploads/files/c011676-nationalreport-ciw_final-s_0.pdf

Carers UK (2019) Facts about carers, policy brief, www.carersuk.org/images/ Facts_about_Carers_2019.pdf.

Carers UK (2020) The Rise in the Number of Unpaid Carers During the Coronavirus (COVID19) Outbreak, Carers Week 2020 Research Report,London: Carers UK, www.carersuk. org/images/CarersWeek2020/CW_2020_Research_Report_WEB.pdf.

Carlos, J. and Wilson, K. (2018) Migration among temporary foreign workers: examining health and access to health care among Filipina live-in caregivers, Social Science and Medicine, 209: 117-24. doi: 10.1016/j.socscimed.2018.05.045 
Clarke, M. and Ravenswood, K. (2019) Constructing a career identity in the aged care sector: overcoming the 'taint' of dirty work, Personnel Review, 48(1): 76-97. doi: 10.1108/PR-08-2017-0244

Clements, L. (2016) Carers and Their Rights, 6th edn, London: Carers UK.

Cunningham, N., Cunningham, T. and Roberston, J. (2018) Understanding and measuring the wellbeing of carers of people with dementia, The Gerontologist, 59(5): e552-64.

Dahlberg, L., Berndt, H., Lennartsson, C. and Schoen, P. (2018) Receipt of formal and informal help with specific care tasks among older people living in their own home: national trends over two decades, Social Policy and Administration, 52(1): 91-110. doi: 10.1111/spol.12295

Dann, T. (2014) Global elderly care in crisis: editorial, The Lancet, 383(9921): 927. doi: 10.1016/S0140-6736(14)60463-3

Da Roit, B. and Moreno-Fuentes, F. (2019) Cash for care and care employment: (missing) debates and realities, Social Policy and Administration, 53(4): 596-611. doi: $10.1111 /$ spol.12503

Delp, L., Wallace, S., Geiger-Brown, J. and Muntaner, C. (2010) Job stress and job satisfaction: home care workers in a consumer-directed model of care, Health Services Research, 45(4): 922-40. doi: 10.1111/j.1475-6773.2010.01112.x

Denton, M., Zeytinoglu, I., Kusch, K. and Davies, S. (2007) Market-modelled home care: impact on job satisfaction and propensity to leave, Canadian Public Policy, 33(Suppl): S81-99. doi: 10.3138/G551-755V-12W7-2551

Department of Health (2014) Care and Support: Statutory Guidance, London: Department of Health, https://assets.publishing.service.gov.uk/government/ uploads/system/uploads/attachment_data/file/315993/Care-Act-Guidance.pdf.

Diener, E., Inglehart, R. and Tay, L. (2013) Theory and validity of life satisfaction scales, Social Indicators Research, 112: 497-527. doi: 10.1007/s11205-012-0076-y

Duncan, K., Shooshtari, S., Roger, K., Fast, J. and Han, J. (2016) Care-related out-ofpocket expenditures in Canada, Journal of Financial Counseling and Planning, 27(2): 277-96. doi: 10.1891/1052-3073.27.2.277

Duncan, K., Shooshtari, S., Roger, K., Fast, J. and Han, J. (2020) The cost of caring: outof-pocket expenditures and financial hardship among Canadian carers, International Journal of Care and Caring, 4(2): 141-66. doi:10.1332/239788220X15845551975572

Edvardsson, D., Fethersonhaugh, D., McAuliffe, L., Nay, R. and Chenco, C. (2011) Job satisfaction among aged care staff: exploring the influence of personcentred care provision, International Psychogeriatrics, 23(8): 1205-12. doi: 10.1017/ S1041610211000159

Elliott, K., Stirling, C., Martin, A., Robinson, A. and Scott, J. (2013) Perspectives of the community-based dementia care workforce: 'occupational communion' a key finding from the Work 4 Dementia project, International Psychogeriatrics, 25(5): 765-74. doi: 10.1017/S1041610212002323

Eurofound (2020) Long-Term Care Workforce: Employment and Working Conditions, Luxembourg: Publications Office of the European Union.

European Commission (2017) An initiative to support work-life balance for working parents and carers, COM (2017) 252 final.

Fast,J. (2015) Caregiving for Older Adults with Disabilities: Present Costs, Future Challenges, Montreal: Institute for Research on Public Policy, https://irpp.org/research-studies/ caregiving-for-older-adults-with-disabilities/. 
Fekete, C., Tough, H., Siegrist, J. and Brinkhof, M. (2017) Health impact of objective burden, subjective burden and positive aspects of caregiving: an observational study among caregivers in Switzerland, BMJ Open, 7(12): 1-9.

Finch, J. (1989) Family Obligations and Social Change, Cambridge: Polity Press.

Gao, F., Newcombe, P., Tilse, C., Wilson, J. and Tuckett, A. (2017) Challenge-related stress and felt challenge: predictors of turnover and psychological health in aged care nurses, Collegian, 24(4): 361-9. doi: 10.1016/j.colegn.2016.07.006

George, E., Hale, L. and Angelo, J. (2017) Valuing the health of the support worker in the aged care sector, Ageing and Society, 37(5): 1006-24. doi: 10.1017/ S0144686X16000131

Gillett-Swan, J. and Sargeant, J. (2015) Wellbeing as a process of accrual: beyond subjectivity and beyond the moment, Social Indicators Research, 121: 135-48. doi: 10.1007/s11205-014-0634-6

Gomez-Leon, M., Evandrou, M., Falkingham, J. and Vlachantoni, A. (2019) The dynamics of social care and employment in mid-life, Ageing and Society, 39(2): 381-408. doi: 10.1017/S0144686X17000964

Graham, C. (2010) Happiness Around the World: The Paradox of Happy Peasants and Miserable Millionaires, Oxford: Oxford University Press.

Hall, D. (2019) New Zealand's living standards framework. What might Amartya Sen say?, Policy Quarterly, 15(1): 38-45. doi: 10.26686/pq.v15i1.5294

Hamblin, K. (2019) Adult Social Care and Wellbeing Policy in the Four Nations of the UK, Sustainable Care Paper No. 1, Sheffield: University of Sheffield, http://circle.group. shef.ac.uk/wp-content/uploads/2019/12/WPO_final-v2.pdf.

Hankivsky, O. (2014) Rethinking care ethics: on the promise and potential of an intersectional analysis, The American Political Science Review, 108(2): 252-64, www. jstor.org/stable/43654371. doi: 10.1017/S0003055414000094

Hebson, G., Rubery, J. and Grimshaw, D. (2015) Rethinking job satisfaction in care work: looking beyond the care debates, Work, Employment and Society, 29(2):314-30. doi: 10.1177/0950017014556412

Hewko, S.J., Cooper, S., Huynh, H., Spiwek, T., Carleton, H., Reid, S. and Cummings, G. (2015) Invisible no more: a scoping review of the health care aide workforce literature, BMC Nursing, 14: 38. doi: 10.1186/s12912-015-0090-x

Huta, V. and Ryan, R. (2010) Pursuing pleasure or virtue: the differential and overlapping well-being benefits of hedonic and eudaimonic motives, Journal of Happiness Studies, 11(6): 735-62. doi: 10.1007/s10902-009-9171-4

ILO (International Labour Office) (2018) Care Work and Care Jobs for the Future of Decent Work, Geneva: International Labour Office, www.ilo.org/global/publications/ books/WCMS_633135/lang--en/index.htm.

Joseph, S., Sempik, J., Leu,A. and Becker, S. (2019) Young carers research, practice and policy: an overview and critical perspective on possible future directions, Adolescent Research Review, 5: 77-89. doi: 10.1007/s40894-019-00119-9

Kaine,S. (2012) Regulation and employee voice in the residential aged care sector, Human Resource Management Journal, 22(3):316-31. doi:10.1111/j.1748-8583.2011.00170.x

Keating, N. and Cheshire-Allen, M. (forthcoming) Policy to reduce late-life social exclusion: from aspirations to action, in K. Walsh, T. Scharf, A. Wanka and S. Van Regenmortel (eds) Social Exclusion in Ageing Societies: Interdisciplinary and Policy Perspectives, New York: Springer. 
Keating, N. and Eales, J. (2017) Social consequences of family care: a scoping review, International Journal of Care and Caring, 1(2): 153-73. doi: 10.1332/239788217X1 4937990731749

Keating, N., Fast, J.E., Lero, D.S., Lucas, S.J. and Eales, J. (2014) A taxonomy of the economic costs of family care to adults, Journal of the Economics of Ageing, 3: 11-20. doi: 10.1016/j.jeoa.2014.03.002

Keating, N., Eales, J., Funk, L., Fast, J.E and Min, J. (2019) Life course trajectories of family care, International Journal of Care and Caring, 3(2): 147-63. doi: 10.1332/23 9788219X15473079319309

Kickbusch, I., Farrar, J. and Challis, M. (2019) A new global health strategy for Germany, The BMJ, 366: 14662.

Kodate, N. and Timonen, V. (2017) Bringing the family in through the back door: the stealthy expansion of family care in Asian and European long-term care policy, Journal of Cross Cultural Gerontology, 32:291-301. doi: 10.1007/s10823-017-9325-5

Koumenta, M. and Williams, M. (2019) An anatomy of zero-hour contracts in the UK, Industrial Relations Journal, 50(1): 20-40. doi: 10.1111/irj.12233

Kramer, B. and Boelk, A. (2015) Correlates and predictors of conflict at the end of life among families enrolled in hospice, Journal of Pain and Symptom Management, 50(2): 155-62. doi: 10.1016/j.jpainsymman.2015.02.026

Kröger, T. and Yeandle, S. (eds) (2013) Combining Paid Work and Family Care: Policies and Experiences in International Perspective, Bristol: The Policy Press.

Lai, D. (2012) Effect of financial costs on caregiving: burden of family caregivers of older adults, SAGE Open, 2(4): 1-14. doi: 10.1177/2158244012470467

Lai, D., Cloyes, K., Clayton, M., Doyon, K., Reblin, M., Beck, A. and Ellington, L. (2018) We're the eyes and the ears, but we don't have a voice: perspectives of hospice aides, Journal of Hospice and Palliative Nursing, 20(1): 47-54. doi: 10.1097/ NJH.0000000000000407

Layard, R. (2006) Happiness: Lessons from a New Science, London: Penguin.

Leichsenring, K., Billings, J. and Nies, H. (eds) (2013) Long-Term Care in Europe: Improving Policy and Practice, Houndmills: Palgrave McMillan.

Leslie, M., Eales, J., Fast, J., Mortensen, W.B., Atoyebi, O. and Khayatzadeh-Mahani, A. (2019) Towards sustainable family care: using goals to reframe the user-centred design of technologies to support carers, International Journal of Care and Caring, 3(3): 445-51. doi: 10.1332/239788219X15597493546652

Lewin, K. (1943) Psychology and the process of group living, Journal of Social Psychology, 17(1): 113-31. doi: 10.1080/00224545.1943.9712269

Lewis, J. and West, A. (2014) Re-shaping social care services for older people in England: policy development and the problem of achieving 'good care', Journal of Social Policy, 43(1): 1-18. doi: 10.1017/S0047279413000561

Lin, S. and Bélanger, D. (2012) Negotiating the social family: migrant live-in elder care-workers in Taiwan, Asian Journal of Social Science, 40(3): 295-320. doi: 10.1163/156853112X650854

Lindberg, S. (2019) Are increasing inequalities threatening democracy in Europe? Carnegie Europe, Reshaping European Democracy Paper, https:// carnegieendowment.org/files/2-1_Lindberg_Inequalities.pdf. 
Mapira, L., Kelly, G. and Geffen, L.N. (2019) A qualitative examination of policy and structural factors driving care workers' adverse experiences in long-term residential care facilities for older adults in Cape Town, BMC Geriatrics, 19: 97. doi: 10.1186/ s12877-019-1105-3

McGregor,J.A. (2007) Researching human wellbeing: from concepts to methodology, in I. Gough and J.A. McGregor (eds) Wellbeing in Developing Countries: From Theory to Research, Cambridge: Cambridge University Press, pp 316-50.

McGregor, J.A. (2018) Reconciling universal frameworks and local realities in understanding and measuring wellbeing, in I. Bache and K. Scott (eds) The Politics of Wellbeing: Theory, Policy and Practice, London: Palgrave Macmillan, pp 197-224.

McGregor, J.A. and Pouw, N. (2017) Towards an economics of wellbeing, Cambridge Journal of Economics, 41(4): 1123-42.

Michalos, A.C. (2011) What did Stiglitz, Sen and Fitoussi get right and what did they get wrong?, Social Indicators Research, 102(1): 117-29. doi: 10.1007/ s11205-010-9734-0

Mizuno, E., Iwasaki, M. and Sakai, I. (2011) Subjective experiences of husbands of spouses with schizophrenia: an analysis of the husbands' descriptions of their experiences, Archives of Psychiatric Nursing, 25(5): 366-75. doi: 10.1016/j. apnu.2011.03.001

Moen, P. and DePasquale, N. (2017) Family care work: a policy-relevant research agenda, International Journal of Care and Caring, 1(1): 45-62. doi: 10.1332/239788 217X14866284542346

Moore, K.J. et al. (2017) Experiences of end of life amongst family carers of people with advanced dementia: longitudinal cohort study with mixed methods, BMC Geriatrics, 17(135): 1-13. doi: 10.1186/s12877-016-0400-5

Mosher, C.E., Given, B.A. and Ostroff, J.S. (2015) Barriers to mental health service use among distressed family caregivers of lung cancer patients, European Journal of Cancer Care (Engl), 24(1): 50-9. doi: 10.1111/ecc.12203

Muers, S. (2018) Culture, Values and Public Policy, Bath: Institute for Policy Research (IPR), www.bath.ac.uk/publications/culture-values-and-public-policy/ attachments/culture-values-and-public-policy.pdf.

Mundlak, G. and Shamir, H. (2011) Bringing together or drifting apart? Targeting care work as 'work like no other', Canadian Journal of Women and the Law, 23(1): 289-308. doi: 10.3138/cjwl.23.1.289

NAO (National Audit Office) (2018) Social care at a glance, www.nao.org.uk/ wp-content/uploads/2018/07/Adult-social-care-at-a-glance.pdf.

New Zealand Treasury (2018) Our People, Our Country, Our Future. Living Standards Framework: Background and Future Work, Wellington: New Zealand Government, https://treasury.govt.nz/sites/default/files/2018-12/lsf-background-future-work.pdf.

OECD (Organisation for Economic Co-operation and Development) (2013) OECD Guidelines on Measuring Subjective Well-being, Paris: OECD Publishing, www.oecd.org/statistics/oecd-guidelines-on-measuring-subjective-well-being9789264191655-en.htm.

OECD (2017) How's Life? 2017: Measuring Well-being, Paris: OECD Publishing, https://doi.org/10.1787/how_life-2017-en.

OECD (2018) Opportunities for All: OECD Framework for Policy Action on Inclusive Growth, Paris: OECD Publishing, http://dx.doi.org/10.1787/9789264301665-en. 
ONS (Office for National Statistics) (2019) Measuring National Well-being in the UK, Domains and Measures: March 2019, London: ONS, www.ons.gov.uk/ peoplepopulationandcommunity/wellbeing/articles/measuringnationalwellbeing/ internationalcomparisons2019.

Palmer, E. and Eveline, J. (2012) Sustaining low pay in aged care work, Gender, Work and Organization, 19(3): 254-75. doi: 10.1111/j.1468-0432.2010.00512.x

Peacock, S., Forbes, D., Markle-Reid, M., Hawranik, P., Morgan, D., Jansen, L., Leipert, B.D. and Henderson, S.R. (2010) The positive aspects of the caregiving journey with dementia: using a strengths-based perspective to reveal opportunities, Journal of Applied Gerontology, 29(5): 640-59. doi: 10.1177/0733464809341471

Rainville, C., Skufca, L. and Mehegan, L. (2016) Family Caregiving and Out-of-Pocket Costs: 2016 Report, Washington:AARP, www.aarp.org/content/dam/aarp/research/ surveys_statistics/ltc/2016/family-caregiving-costs.doi.10.26419-2Fres.00138.001. pdf.

Rand, S. and Malley, J. (2014) Carers' quality of life and experiences of adult social care support in England, Health and Social Care in the Community, 22(4): 375-85. doi: $10.1111 /$ hsc. 12089

Reczek, C. and Umberson, D. (2016) Greedy spouse, needy parent: the marital dynamics of gay, lesbian, and heterosexual intergenerational caregivers, Journal of Marriage and Family, 78(4): 957-74. doi: 10.1111/jomf.12318

Roberto, K. and Blieszner, R. (2015) Diverse family structures and the care of older persons, Canadian Journal on Aging/La Revue Canadienne Du Vieillissement, 34(3): 305-20. doi: 10.1017/S0714980815000288

Rossen, C., Stenager, E. and Buus, N. (2013) The experiences of being close relatives and informal carers of mentally ill Iraqi refugees: a qualitative study, International Journal of Culture and Mental Health, 7(4): 452-63. doi: 10.1080/17542863.2013.855247

Sardadvar, K. and Mairhuber, I. (2018) Employed family carers in Austria, Österreichische Zeitschrift für Soziologie, 43: 61-72, https://doi.org/10.1007/s11614-018-0283-0.

Sen,A. (1999) Commodities and Capabilities, Oxford: Oxford University Press, https:// ideas.repec.org/b/oxp/obooks/9780195650389.html.

Shanas, E. (1979) The family as a social support system in old age, The Gerontologist, 19(2): 169-74, doi: 10.1093/geront/19.2.169

Skills for Care (2020) The Size and Structure of the Adult Social Care Sector and Workforce in England, 2019/20, Leeds: Skills for Care, www.skillsforcare.org.uk/adult-socialcare-workforce-data/Workforce-intelligence/publications/national-information/ The-size-and-structure-of-the-adult-social-care-sector-and-workforce-in-England. aspx.

Spasova, S., Baeten, R., Coster, S., Ghailani, D., Peña-Casas, R. andVerhercke, B. (2018) Challenges in Long-Term Care in Europe: A Study of National Policies, European Social Policy Network (ESPN), Brussels: European Commission, https://doi.org/10.1093/ eurpub/ckw229.

Stephens, C. and Breheny, M. (2019) Health Ageing: A Capability Approach to Inclusive Policy and Practice, Abingdon, Oxfordshire: Routledge.

Stiglitz, J.E. (2020) GDP is the wrong tool for measuring what matters, Scientific American, 323(2): 24-31.

Stiglitz,J.E., Sen,A. and Fitoussi,J.P. (2009) Report by the Commission on the Measurement of Economic Performance and Social Progress, Paris: Sustainable Development, Commission on the Measurement of Economic Performance and Social Progress. 
Taylor, D. (2011) Wellbeing and welfare: a psychosocial analysis of being well and doing well enough, Journal of Social Policy, 40(4): 777-94. doi: 10.1017/ S0047279411000249

Tronto, J. (2013) Caring Democracy: Markets, Equality, and Justice, New York: New York University Press.

Tronto, J. (2017) There is an alternative: homines curans and the limits of neoliberalism, International Journal of Care and Caring, 1(1): 27-43. doi: 10.1332/239788217X14 866281687583

UNDP (United Nations Development Programme) (2017) UNDP's Strategy for Inclusive and Sustainable Growth, New York: UNDP, www.undp.org/content/undp/ en/home/librarypage/poverty-reduction/undp_s-strategy-for-inclusive-andsustainable-growth.html.

UNGA (United Nations General Assembly) (2015) Transforming our world: the 2030 agenda for sustainable development, Resolution 70/1, September, www.unfpa.org/resources/transforming-our-world-2030-agenda-sustainabledevelopment \#: :text=On\%2025\%20September\%2C\%20the\%20United,2030\%20 Agenda\%20for\%20Sustainable\%20Development. \&text $=$ We $\% 20$ are $\% 20$ committed $\% 20$ to $\% 20$ achieving,a $\% 20$ balanced $\% 20$ and $\% 20$ integrated $\% 20$ manner.

Van Houtven, C.H., Coe, N.B. and Skira, M.M. (2013) The effect of informal care on work and wages, Journal of Health Economics, 32(1): 240-52. doi: 10.1016/j. jhealeco.2012.10.006

Virdo, G. and Daly, T. (2019) How do supervisor support and social care matter in long-term care? Correlates of turnover contemplation among long-term care facility workers, International Journal of Care and Caring, 3(3): 413-24. doi: 10.1332 /239788218X15411705353061

Waring, M. (2004) Counting for Nothing: What Men Value and What Women are Worth, 2nd edn, Toronto: University of Toronto Press.

Waring, M. (2018) Still Counting:Wellbeing,Women's Work and Policy-Making,Wellington, New Zealand: Bridget Williams Books.

WEF (World Economic Forum) (2017) The Inclusive Growth and Development Report 2017, Geneva: World Economic Forum, www.weforum.org/reports/theinclusive-growth-and-development-report-2017\#: :text $=$ The $\% 20$ report $\% 2 \mathrm{C} \% 20$ which $\% 20$ covers $\% 20109$,to\%20work $\% 2$ C\%20save $\% 20$ and $\% 20$ invest.

Wilkinson, R. and Pickett, K. (2009) The Spirit Level:Why More Equal Societies Almost Always Do Better, London: Allen Lane.

Yeandle, S. (2020) Peer review on 'Work-life balance: promoting gender equality in informal long-term care provision', thematic discussion paper, European Commission, DG Employment, Social Affairs and Inclusion.

Yeandle, S. and Buckner, L. (2007) Caring, Employment and Services: Time for a New Social Contract?, CES Report No. 6, London: Carers UK.

Yeandle, S., Kröger, T. and Cass, B. (2012) Voice and choice for users and carers? Developments in patterns of care for older people in Australia, England and Finland, Journal of European Social Policy, 22(4): 432-45. doi: 10.1177/0958928712449775

Zarit, S., Todd, P. and Zarit, J. (1986) Subjective burden of husbands and wives as caregivers: a longitudinal study, The Gerontologist, 26(3): 260-6. doi: 10.1093/ geront/26.3.260 